\title{
Electrical Impedance Tomography of the 1995 OGI Gasoline Release
}

\author{
W. Daily
}

A. Ramirez

October 1, 1996

This is an informal report intended primarily for internal or limited external distribution. The opinions and conclusions stated are thowe of the author and may or may not be those of the Laboratory.

Work performed under the aupices of the U.S. Department of Energy by the Lawrence Livermore National Laboratory under Contract W-7405-Eng-18. 


\section{DISCLAIMER}

Thls document was prepared as an account of work sponsored by an agency of the United States Government. Neither the United States Government nor the University of Callfornia nor any of their employees, makes any warranty, express or implled, or assumes any legal liability or responsibility for the accuracy, completeness, or usefulness of any information, apparatus, product, or process disclosed, or represents that its use would not Infringe privately owned rights. Reference herein to any spectinc commerdal products, process, or service by trade name, trademark, manwacturer, or otherwise, does not necessarliy constitute or imply its endorsement, recommendation, or favoring by the United States Government or the University of Callfornia. The vlews and opInions of authors expressed herein do not necessarily state or reflect those of the United States Government or the University of Califorala, and shall not be used for advertising or product endorsement purposes.

This report bas been reproduced directly frow the best avaliable copy.

Avallable to DOE and DOE contractors from the Omice of Sclentific and Technical Information

P.O. Box 62, Oak Ridge, TN 37831

Prices available from (615) 576-8401, FTS 626-8401

Avallable to the public from the National Technleal Information Service

U.S. Department of Commerce 5285 Port Royal Rd, Springfield, VA 22161 


\title{
Electrical Impedance Tomography of the 1995 OGI Gasoline Release
}

\author{
William Daily and Abelardo Ramirez \\ Lawrence Livermore National Laboratory \\ Livermore, CA 94550
}

October 1996

\begin{abstract}
:
Electrical impedance tomography (EIT) was used to image the plume resulting from a release of 378 liters (100 gallons) of gasoline into a sandy acquifer. Images were made in 5 planes before and 5 times during the release, to generate a detailed picture of the spatial as well as the temporal development of the plume as it spread at the water table.

Information of the electrical impedance (both in phase and out of phase voltages) was used at several different frequencies to produce images. We observed little dispersion in the images either before or after the gasoline entered the acquifer. Likewise, despite some laboratory measurements of hydrocarbon contamination in soil causing phase shifts in measured impedances, there was no evidence of a change in the reactance (IP effect) in the soil because of the gasoline.
\end{abstract}

\section{Background}

\section{Description of EIT}

Electrical impedance tomography (EIT) is a technique for reconstruction of subsurface electrical impedance (or resistivity if the ground is not reactive in nature). The result of such a reconstruction is a 2 or 3 dimensional map of the electrical resistivity distribution underground made from a series of voltage and current measurements from buried electrodes. The EIT approach we follow here relies on detection and mapping of the changes in electrical resistivity associated with a leak. But the technique can be used to map subsurface liquids that flow during natural or man-induced processes and to map geologic structure. For example, man-induced processes such as tank leaks (Ramirez et al., 1996) and clean-up processes such as steam injection (Ramirez et al., 1993), can create changes in a soil's electrical properties that are readily measured and imaged. 
To do EIT surveys we place a number of electrodes in boreholes and/or at the ground surface to image the resistivity distribution between two boreholes. Using an automatic data collection and switching system, we collect a few hundred electrical impedance measurements. The data is then processed to produce electrical tomographs using state of the art data inversion algorithms.

In the simplest of circuits, the voltage drop across a resistor is in phase with the current flowing through the resistor and the ratio of the instantaneous voltage and current is a constant (Ohm's law) called the resistance. In general, however, the voltage and current will not be in synchronization so that the two are often represented as complex quantities, in which case Ohm's law still applies but yields a complex quantity or impedance. If the current leads the voltage the impedance is called reactive and if the current lags the voltage it is called inductive (terms arising from the behavior of lumped circuits of capacitors and inductors). We will present images inverted from both the real and imaginary components of measured impedance.

There is one more complication which we must consider and that is the fact that resistance (or impedance) may vary with frequency--a property called dispersion. We will also present images inverted from measurements at various frequencies to indicate any electrical dispersion which might be present in the subsurface.

\section{Description of 2D algorithm}

Here we describe briefly some of the important features of the 2D inversion algorithm. For additional details, the reader is referred to LaBrecque et al. (1996). The algorithm involves solving both the forward and inverse problems. The solution to the forward problem uses the finite element method (FEM) to compute the potential electrical response of a 2-D earth to a 3-D source. To avoid the difficulty of numerically solving a 3-D problem, Poisson's equation is formulated in the wave-number domain using the Fourier transformation in the strike $(y)$ direction. The governing equation is

$$
\frac{\partial}{\partial x}\left(\sigma \frac{\partial V}{\partial x}\right)+\frac{\partial}{\partial z}\left(\sigma \frac{\partial V}{\partial z}\right)-\lambda^{2} \sigma V=-\delta(x) \delta(z)
$$

where $V$ is the potential in the Fourier transform domain, $s$ is the 
conductivity, $l$ is the Fourier transform variable, $I$ is the source current, and $d(\mathrm{x})$ is the delta function (Hohmann, 1986). Our 2-D FEM algorithm is based on the theory described by Huebner and Thornton (1982), and our implementation of it follows that described by Wannamaker et al. (1987) for modeling 2-D magnetotelluric data.

Using the FEM, we can calculate the potentials for a discrete number of transform variables at the nodes of a mesh of quadrilateral elements. We can then transform the potentials back into the Cartesian domain using the method described by LaBrecque (1989). The inverse algorithm iteratively finds the maximum value of the stabilization parameter $a$ to minimize the objective function

$$
Y(\mathbf{P})=\chi^{2}(\mathbf{P})+\alpha W(\mathbf{P})
$$

gives a value of $\mathbf{c 2}(\mathbf{P})$ equal to an a priori value; here $\mathbf{P}$ is the vector of unknown parameters, $W(\mathbf{P})$ is the roughness operator (Tikhonov and Arsenin, 1977), and $\mathrm{c2}$ is the chi-squared statistic. In our work, the a priori value of $\mathrm{c2}^{2}$ is assumed to be equal to the number of data points. The inverted parameters are the natural logarithms of the conductivities of pixels. Each pixel contains the elements of a rectangular region of a FEM mesh. The chi-squared statistic is given b y

$$
\chi^{2}=[\mathbf{D}-\mathbf{F}(\mathbf{P})]^{\mathrm{T}} \mathbf{w}^{-1}[\mathbf{D}-\mathbf{F}(\mathbf{P})]
$$

where $\mathbf{D}$ is the vector of known data values and $\mathbf{W}$ is the data covariance matrix. The roughness operator stabilizes and removes ambiguity in the resistivity inversion by minimizing the model roughness; this is referred to as smoothest inversion. The roughness operator $W(\mathbf{P})$ is given by

$$
W(\mathbf{P})=\mathbf{P}^{\mathrm{T}} \mathbf{R}(\mathbf{P})
$$

here $\mathbf{R}$ is the roughness matrix, which is a numerical approximation to the 2-D Laplacian operator (Sasaki, 1992).

At the ith iteration, our algorithm begins by approximating the forward solution by a first-order Taylor's series of the form

$$
\mathbf{F}(\mathbf{P}) \approx \mathbf{F}\left(\mathbf{P}_{i}\right)+\mathbf{A}\left(\mathbf{P}+\mathbf{P}_{i}\right)
$$


where $\mathbf{A}$ is the sensitivity matrix and $\mathbf{P}_{i}$ is the vector of estimated parameters at the $i$ th iteration.

Using a root-finding algorithm, we estimate $a$ for this linearized system. We then use a modified Marquardt method iteration (Bard, 1974) to find the parameters that minimize the objective function [(Eq. (2)] for the estimated value of $a$. Iteration is repeated until the changes in $a$ and $c^{2}$ from one iteration to the next are suitably small.

\section{Experimental Setup}

\section{Data Acquisition System}

ZOMBIE, our state of the art data acquisition system, has four basic components: transmitter or current source; receiver which measures the transmitted current as well as the resulting electrode potentials; multiplexer for connecting the electrodes to the transmitter and receiver; a computer for system control and data archival. A block diagram of the system is shown in Figure 1. We now summarize the capabilities of each of these components:

\section{Transmitter}

The current source is powered by a 125 volt, $400 \mathrm{~Hz}$ generator. The output square wave is synchronized with the receiver by an electrically isolated connection or by an internal crystal clock. The output can be regulated to either constant current or constant voltage for a maximum of $3 \mathrm{k}$ watts output.

\section{Receiver}

The heart of the system is a multichannel detector capable of supporting up to 16 modular detectors, each with a10 $\mathrm{M}$ ohm input impedance at $\mathrm{DC}$, a 16-bit $\mathrm{A} / \mathrm{D}$ converter and a dynamic range from $\pm 0.03 \mu \mathrm{v}$ to $\pm 32 \mathrm{v}$. This large dynamic range is an important attribute when acquiring EIT data since electrode combinations are used in imaging which yield a large variation in received voltage. There is an automatic SP offset adjustment of up to $\pm 2.25 \mathrm{~V}$ in $65 \mu \mathrm{V}$ steps. Each channel has automatic gain setting in binary steps from 1 to 65,536 , but a with manual override the gains may be set externally-a time saving feature when high data rates are needed. Calibration of each channel can be accomplished against either an internal or externally supplied reference voltage. 
In practice one channel is used to measure the transmitted current as a voltage drop across a calibrated resistor in the transmitter circuit. This leaves 15 channels for simultaneous potential measurements and is a major reason for the increase in data acquisition rate of ZOMBIE over single channel systems.

The receiver operates in both the frequency domain and time domain. Twenty four frequencies can be selected in binary intervals between $0.0007 \mathrm{~Hz}$ and $8 \mathrm{kHz}$ and over this range both the signal magnitude and phase can be measured.

\section{Multiplexer}

Inherent in the switching scheme is the use of "dumb" electrodes. This means that the switching is accomplished at a central point and is not distributed to the individual electrode positions as in many "smart" electrode systems. "Dumb" electrodes require that a separate wire connect the central switching bank (multiplexer) and each electrode. Although this requires more wire and sometimes more field set up time, it makes for disposable electrodes--the only type which can be grouted into boreholes in any significant number at reasonable cost. Since our strategy is to position electrodes underground, as close as possible to the imaged region, ZOMBIE requires "dumb" electrodes with a central multiplexer.

The multiplexier system is modular. Each module can address 30 separate "dumb" electrodes and modules can be daisy-chained together to handle multiples of 30 electrodes. Control of each module is via RS232 protocol such that any electrode can be connected to either high or low side of the current source or the high or low side of any detector. Contributing to the overall system data acquisition rate is the switching speed which is $100 \mathrm{~ms}$. The multiplexer switches are rated at 10 amperes at 500 volts.

\section{Computer}

System control is via RS232 protocol from a notebook computer to the receiver and multiplexer. The control software is written in a graphical interface language which is very user friendly.

All of the essential front panel controls on the receiver can be set remotely via the RS232 link: time domain or frequency domain operation, source frequency, stacking, analog stage power line filters, and amplifier gains. Data is downloaded in real time from the 
receiver to the computer and displayed so that the operator can easily monitor data acquisition.

The multiplexer control allows for complete freedom in specifying which electrodes are used for current source and which are used for potential measurement. This protocol is specified by the user in an ASCII file read by the control program.

\section{System performance}

The following summary of system performance is drawn from experience during the work reported herein and from laboratory tests

Data acquisition speed

Data rates are determined by the number of channels which could be continuously used, source frequency and staking requirements. Under normal conditions, at $64 \mathrm{~Hz}$ and staking for $1 \mathrm{sec}$, it is possible to acquire data with about $1 \%$ error (as determined by comparing reciprocal measurements) at a rate of 3077 transfer resistance measurements per hour (mph). This data rate could be increased by pre measuring the analog amplifier gains for each measurement and using these gain settings instead of allowing the system to determine them before each measurement. Using prerecorded gains the data rate increases to about $4000 \mathrm{mph}$. However, prerecorded gains have been used only in laboratory tests and not in field data acquisition.

\section{Data accuracy}

Accuracy is usually defined as "the conformity of an indicated value to an accepted standard value, or true value" (precision, on the other hand, is the "degree of exactness with which a quantity is stated") (Considine, 1983). As one measure of system accuracy we have performed a simple system calibration against a NIST standard. One channel was used to measure the current through a standard resistor (with a NIST pedigree) while another channel was used to measure the resulting potential drop. Table 1 shows data from calibration of one channel where the measured resistance was accurate to better than $1 \%$. This is a check of the routine field calibration.

Unfortunately, this calibration is only a lower limit of the errors in field data where electrode noise, cable coupling, external noise sources, etc. will combine to increase the errors and decrease accuracy. Maximizing data accuracy on a system where errors may vary from one electrode pair to another, or even change with time, is 
a difficult problem. Equally important, but just as difficult to obtain, is a reliable measure of accuracy since fitting the forward model calculations

Table 1

\begin{tabular}{llllll}
$\begin{array}{l}\text { NIST } \\
\text { standard } \\
\text { ohms }\end{array}$ & resistor, & \multicolumn{4}{c}{ ZOMBIE measurements, ohms } \\
& first & error & second & error \\
400.03 & 403.42 & $+0.85 \%$ & 402.30 & $+0.57 \%$ \\
100.00 & 100.80 & $+0.80 \%$ & 100.54 & $+0.54 \%$ \\
198.17 & 199.53 & $+0.68 \%$ & 199.14 & $+0.49 \%$
\end{tabular}

to the measured data to an arbitrarily close tolerance can lead to obviously incorrect inversions (see LaBrecque et al., 1996). Clearly, data accuracy and estimates of that accuracy are important factors in determining overall image quality.

Several measures are used to estimate data accuracy. The most common is repeatability but our experience has been that this test leads to a serious underestimate of error. We have found that reciprocity is a better estimate of error (for a normal 4 electrode measurement of transfer resistance, the reciprocal is found by interchanging the current source and potential measurement electrodes).

The actual errors estimated using this method are dominated by sources other than the data acquisition electronics: electrode material, formation resistivity, formation electrochemistry, ambient electromagnetic noise, etc. Despite this, it is useful to show here typical errors in field data as an illustration of overall system performance. Figure 2 shows the difference between a normal and reciprocal transfer resistance (our estimate of error) for typical $1 \mathrm{~Hz}$ field data. What is actually plotted is the largest error out of 10 different measurements for each transfer resistance and its reciprocal. This is probably an overestimate of error on an individual measurement. Notice that this estimate yields errors 
typically between about 1 and $10 \%$ and that there is a weak correlation with the transfer resistance magnitude.

\section{Tank Layout}

A total of six electrode arrays were used to generate 2D images in five planes. The arrangement allows for one cross section diagonally through the tank using the coplanar arrays L1, L2, L3 and L4 while arrays L5 and L6 were used in conjunction with L3 to produce image planes adjacent to that section (see Figure 3). Each array contained 10 lead electrodes spaced evenly between $25 \mathrm{~cm}$ and $250 \mathrm{~cm}$ depth.

One hundred gallons of unleaded gasoline was released at a single point on the surface approximately midway between EIT arrays L2 and L3. The release rate was $80 \mathrm{ml} / \mathrm{m}$. The phreatic surface was held at $90 \mathrm{~cm}$ depth during the entire experiment. For more a detailed description see Mazella et al., (1996).

EIT data was collected each day at 1,64 and $512 \mathrm{~Hz}$ between planes L1-L2, L2-L3, L3-L4, L5-L3 and L3-L6 during the release, and three times after the release ended. This amounted to 3,300 transfer impedances measured each day or nearly 53,000 measurements over the course of the experiment. The magnitude of these data files underscores two points. First, automated high speed data acquisition was essential for success of the project. Second, reconstructed images shown in the next section represent a high information density.

\section{Results and Discussion}

\section{Hz Data}

Reconstructions will be displayed with planes L1-L2-L3-L4 in one panel representing a $5.63 \mathrm{~m}$ section through the tank. Planes L5-L3L6 are displayed in another panel representing a noncoplanar section intersecting the first section at hole L3.

The baseline images at $1 \mathrm{~Hz}$ are shown in the top row of panels of Figure 4. The resistivity, which varies between 1 and $6 \times 10^{5} \mathrm{~m} \mathrm{ohm}$ $\mathrm{m}$, is fairly uniform as might be expected for a clean sand deposited in the tank with no effort to create any structure. Resistivity of natural soils on this same spatial scale can easily vary by one or two orders of magnitude. The zone of highest resistivity stretches across all image planes above the water table. However, even this zone is 
not uniformly resistive. The left part of plane L2-L3 and the outer edges of L5-L3-L6 are less resistive, probably as a result of heterogeneity in the sand. Another resistive zone appears in the bottom part of plane L3-L4. This irregular shaped anomaly may be a remnant of the air sparging conducted in the tank about 20 days before this time. An air injection well was located just $41 \mathrm{~cm}$ from this plane and there is probably some entrained air remaining in the formation near this well. We saw similar long term behavior after an earlier sparging event (Daily et al., 1995).

Data for the baseline images in Figure 4 were acquired the morning of September 11, 1995. The gasoline release began at 1630 hours the same day and then another EIT data set was taken for all planes (which required about 2 hours) after about 19 liters had been released. The second panel shows those reconstructions after pixel by pixel subtraction of the background images. (Plane L3-L4 did not always converge.) These difference images show only changes in resistivity distribution. At this time changes were generally less than $10 \mathrm{ohm} \mathrm{m}$. Those in the saturated sand may be the result of degassing from the sparging, while changes in the unsaturated zone, especially in plane L2-L3, may be early effects of LNAPL.

The next data (third row of images Figure 4), on September 12 about 18 hours and 86.4 liters into the release, clearly shows a 10 to 40 ohm $\mathrm{m}$ resistive anomaly forming directly above the water table in L2-L3 and L5-L3-L6. Notice, however, that it is not uniform or even continuous. In fact, the largest resistivity changes may not be directly beneath the release point but rather in plane L3-L5. We believe these anomalies are an indirect indicator of the LNAPL (Daily et al., 1995) moving into a soil of heterogeneous permeability. We point out that the LNAPL anomaly in plane L2-L3 is influenced by the small aspect ratio (height/width) of that image plane. Because we sample the image planes only along the sides, a small aspect ratio means poor sampling, especially in the image center, resulting in reduced sensitivity and resolution there. As a result, direct comparison of the LNAPL anomaly in this plane and others in high aspect ratio planes, can be missleading. The actual electrical contrast of the LNAPL anomaly in plane L2-:L3 is higher than what is shown.

There are several mechanisms which might be responsible for the resistivity changes associated with the LNAPL. First, is a spatial redistribution of the pore water in the capillary fringe as a result of changes in the pore water suction potential when the water-air 
tend to provide less of a barrier for the plume to spread laterally, thereby producing a thinner plume.

We emphasize here that the LNAPL anomaly is relatively obvious in these tomographs because we have presented difference images which have the natural background variability removed. The real need, of course, is to image a LNAPL plume with out the benefit of this subtraction since in most cases the image of pristine soil is not available. We have processed these images in various ways in an attempt to delineate the LNAPL without using the background data. To date we have been unable to separate the relatively small contrast of the plume from the much larger variations in natural resisitivty in such a way that the plume can be imaged in the presence of the natural variability. Because the tank contents were installed with a single type of fairly homogenized sand, this environment should be a much easier case than most in the realworld.

\section{$64 \mathrm{~Hz}, 256 \mathrm{~Hz}$ and $512 \mathrm{~Hz}$ Data}

Figure 5 shows the inversion of selected $512 \mathrm{~Hz}$ data. The most obvious feature of the resistivity inversions and differences is their similarity to the $1 \mathrm{~Hz}$ results. In fact, we believe that over this frequency range and within the instrumental accuracy, there is no observable dispersion in the data; that is, the impedance does not depend significantly on frequency. The figure also shows the inversion of phase data for the same planes. These images were produced by separate inversion of the real and imaginary data and then the calculation of theta as the acrtangent of a pixel by pixel ratio. Notice that theta is between 0 and $30 \mathrm{~m} \mathrm{rad}$, values within the measurement system error at this frequency. Therefore, we believe that below $512 \mathrm{~Hz}$ there is little reactive component in the data; that is, the impedance is mostly resistive.

Figure 5 is only the second time that dispersion and reactance of the subsurface have been imaged (see Daily and Ramirez, 1996). These results are important because of the recent reports by Olheoft (1986), Borner et al. (1993) and Vanhala (1996) that laboratory soil samples exhibit both reactive and dispersive electrical behavior when contaminated by hydrocarbons. It is important to note, however, that these laboratory results likely depended on the 
presence of clay to catalyze the observed electrochemistry (Olheoft, 1986) and there was no clay in the soil in the tank.

\section{Ackowldgements}

We recognize the contributions of the following colleagues at Lawrence Livermore National Laboratory J. Carbino and J. Beatty and the following colleagues at the Oregon Graduate Institute of Science and Technology Dr. Rick Johnson, W. Bagby and M. Perrot. The support and technical advice from Aldo Mazella was important to the success of this project. This work was sponsored by the Environmental Protection Agency.

This study was performed under the auspices of the U.S. Department of Energy by Lawrence Livermore National Laboratory under contract W-7405ENG-48.

\section{REFERENCES}

Bard, Y., Nonlinear Parameter Estimation (Academic Press, New York), pp. 111-113,1974.

Borner, F., M. Gruhne and J. Schon, Contamination indications derived from electrical properties in the low frequency range, Geophysical Prospecting, 41, 83-98, 1993.

Considine, D. M., Van Nostrand's Scientific Encyclopedia, Sixth Edition, Van Nostrand Reinhold, Inc., 1983.

Daily, W., A. Ramirez, D. LaBrecque and W. Barber, Electrical Resistance Tomography at the Oregon Graduate Institute Experiment, J. of Applied Geophysics, 33, 227-237, 1995.

Daily, W. and A. Ramirez, Electrical Impedance Tomography of the 1995 OGI Perchloroethelyne Release, UCRL, September, 1996.

Hohmann, G. W., 1988, "Numerical Modeling for Electromagnetic Methods in Geophysics," in Nabighian, M. N., Ed., Electromagnetic Methods in Geophysics, 1: Soc. Expl. Geophys., Invest. in Geophys., no. 3, 313-363, 1986.

Huebner, K. H., and E. A. Thornton, The Finite Element Method for Engineers (Wiley, New York),1982. 
LaBrecque, D. J., Cross-Borehole Resistivity Modeling and Model Fitting, Ph.D. thesis, University of Utah, 1989.

LaBrecque, D. J., M. Miletto, W.Daily, A. Ramirez and E. Owen, The Effect of Noise on OCCAM's Inversion of Resistivity Tomography Data,Geopohysics, 61, 538-548, March-April 1996.

Mazella et al., (1996). same journal-describe experiment

Olhoeft, G. R., Direct Detection of Hydrocarbon and Organic Chemicals with Ground Penetrating Radar and Complex Resistivity, Proc. of the NWWA/API Conf. on Petroleum Hydrocarbons and Organic Chemicals in Ground Water--Prevention, Detection and Restoration, The Westin Galleria, Houston, Texas, 12-14 November, 1986.

Ramirez, A., W. Daily, A. Binley, D. LaBrecque and D. Roelant, Detection of Leaks in Underground Storage Tanks Using Electrical Resistance Methods, UCRL-JC-122180, October, J. Engineering and Environmental Geophysics, in press, 1996.

Ramirez, A., W. Daily, D. LaBrecque, E. Owen and D. Chesnut, Monitoring an Underground Steam Injection Process Using Electrical Resistance Tomography, Water Resources Research, vol. 29, no. 1, pp 73-88, 1993.

Sasaki, Y., "Resolution of Resistivity Tomography Inferred from Numerical Simulation," Geophysical Prospecting 40, 453-463,1992.

Tikhonov, A. N. and Arsenin, V. Y., Solutions of ill-posed problems, ed. Fritz, J., John Wiley \& Sonss, New York,1977.

Vanhala, H., Pollution Monitoring Using Spectral Induced Polarization (Spectral IP) Method, Proc. Environmental and Engineering Geophysics Soc., European Section, Mantes, France, 173-176, 2-5 September 1996.

Wannamaker, P. E., J. A. Stodt, and L. Rijo, PW2D Finite Element Program for Solution of Magnetotelluric Responses of TwoDimensional Earth Resistivity Structure, DOE/SAN/12196-13, Univ. of Utah Research Institute, Earth Science Laboratory report ESL-158, 1987. 
Figure Captions

Figure 1. Block diagram of ZOMBIE, our data acquisition system.

Figure 2. Difference between the normal and reciprocal transfer resistance as a function of transfer resistance for $1 \mathrm{~Hz}$ field data.

Figure 3. Plan view of borehole layout used for EIT in the experiment.

Figure 4. EIT results for data acquired at $1 \mathrm{~Hz}$. The first row are baseline images taken on 09/11, before the release started. The arrow shows the LNAPL release point in plane L2-L3, the dashed line is the location of the water table and the color scale is linear. Below the baseline data are difference images taken during the gasoline release.

Figure 5. Inversion of complex resistivity and frequency dependent resisitvity. The baseline images of $512 \mathrm{~Hz}$ resistivity magnitude are included for reference. The next two rows are difference images of changes in resistivity at $512 \mathrm{~Hz}$ on $09 / 11$ (same day as release started) and on 09/16. The last row are images of $512 \mathrm{~Hz}$ impedance phase for the baseline data.

Table 1. ZOMBIE calibration data 


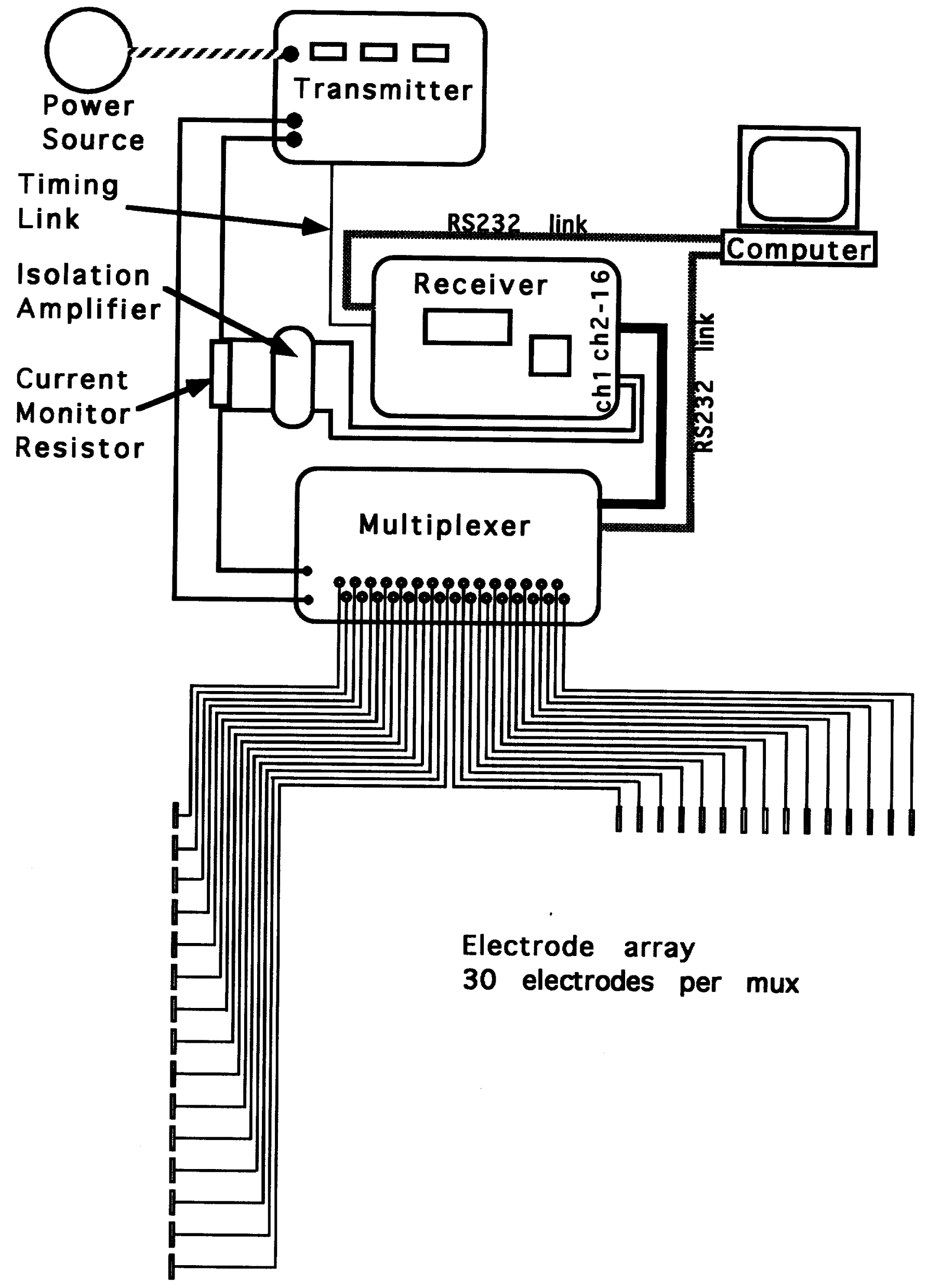




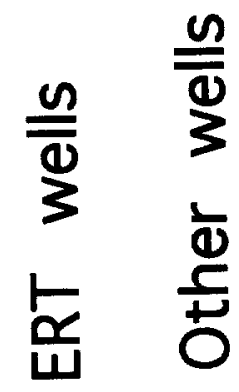

$$
\begin{aligned}
& \square
\end{aligned}
$$

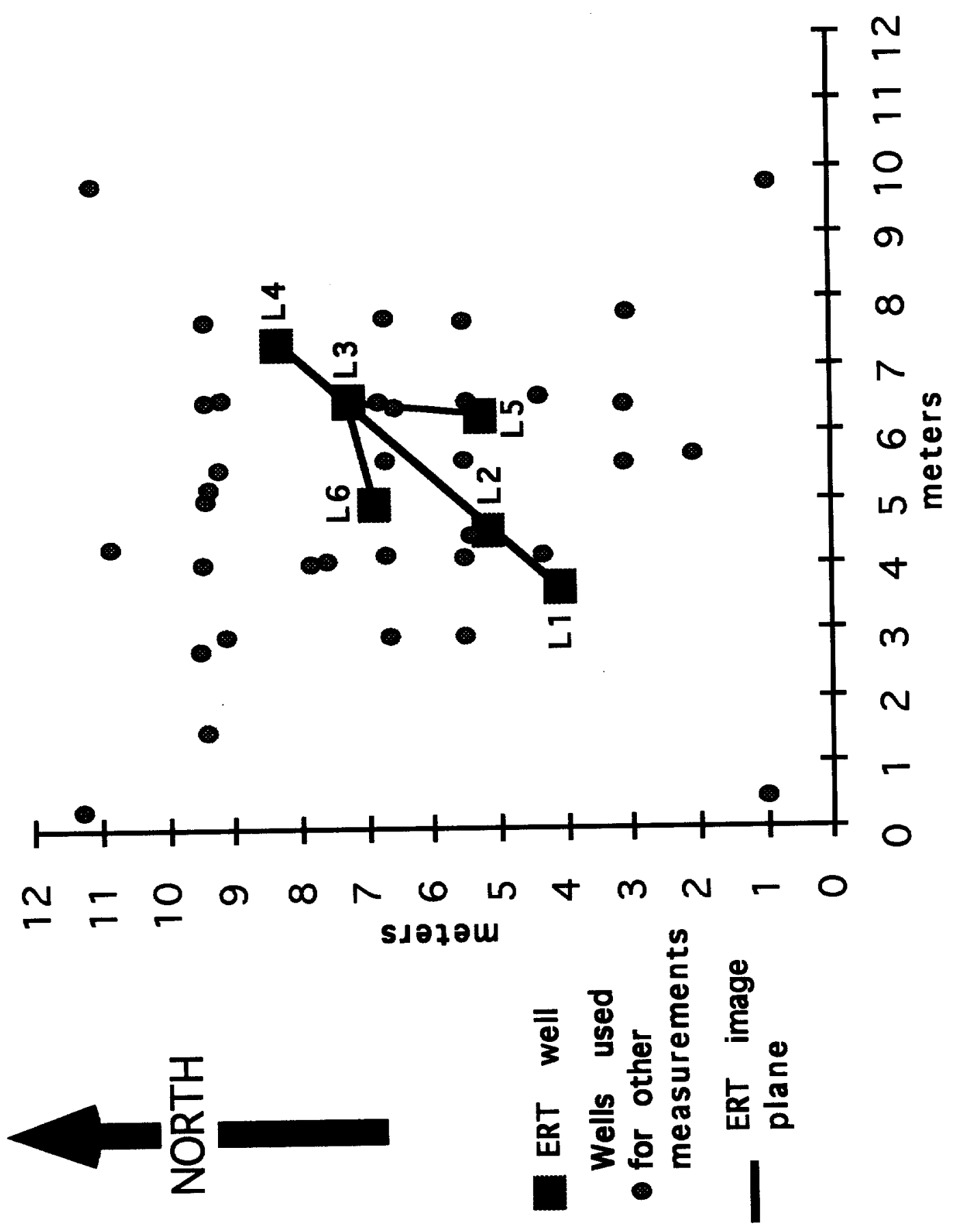




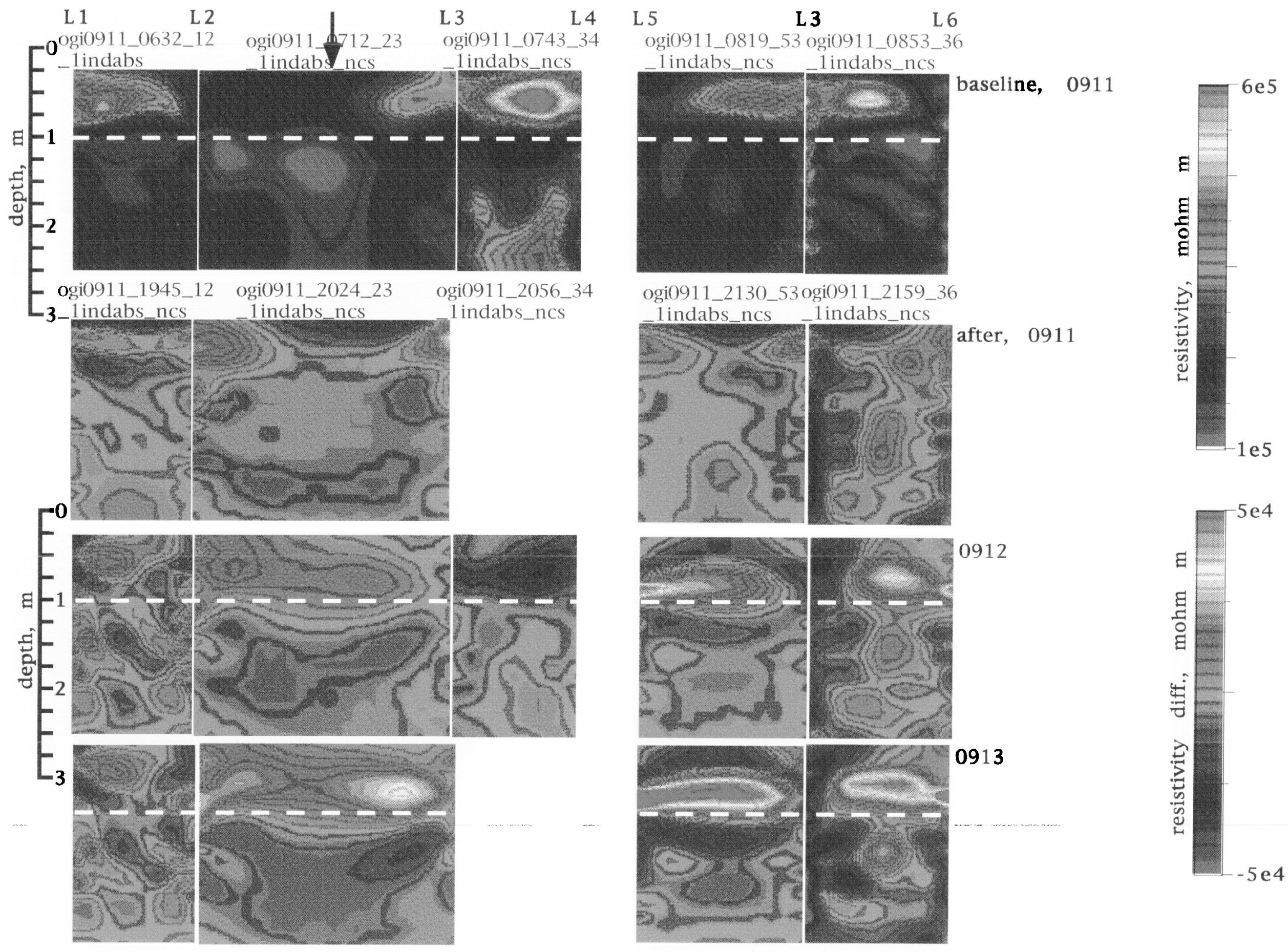




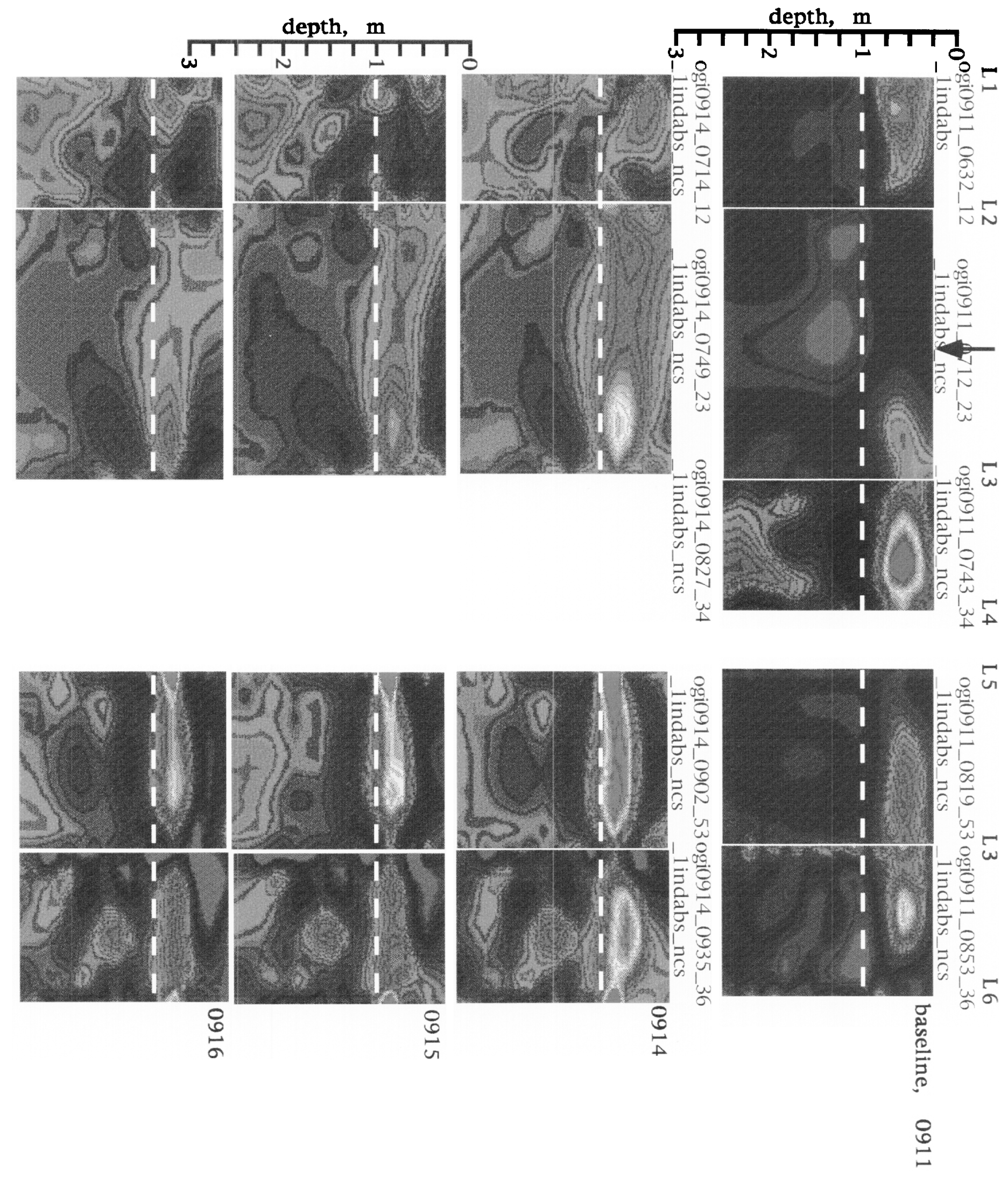

resistivity diff., mohm $\mathrm{m}$

resistivity, mohm $\mathrm{m}$

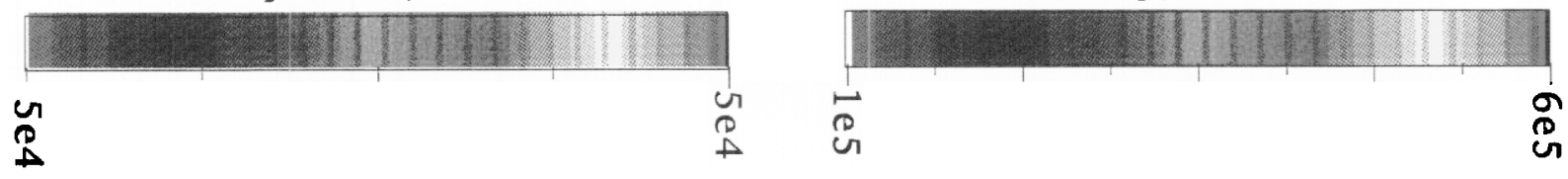




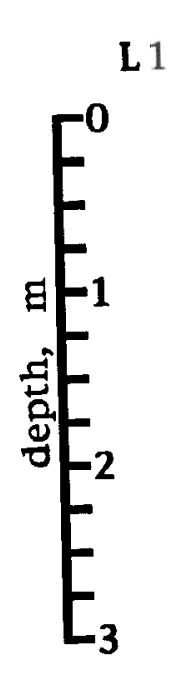

$E_{3}$ L 2 L 3 $\quad$ ogi0911_0806_34 ogi0911_ $733 \_23$ sindars ncs 512indabs_ncs

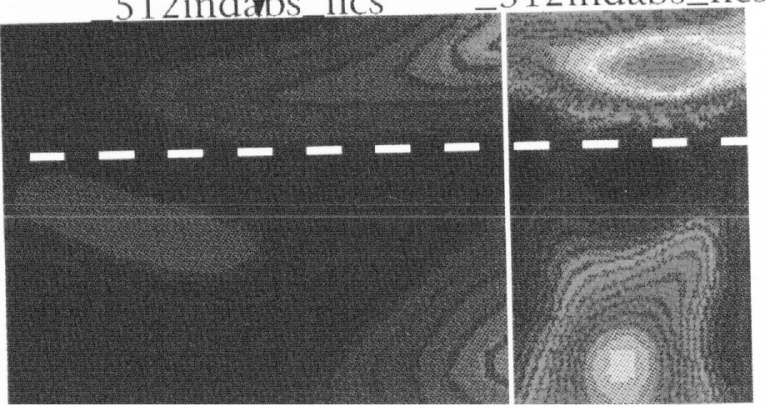

ogi0911_2043_23

ogi0911_2118_34 512indabs_ncs 512indabs_ncs
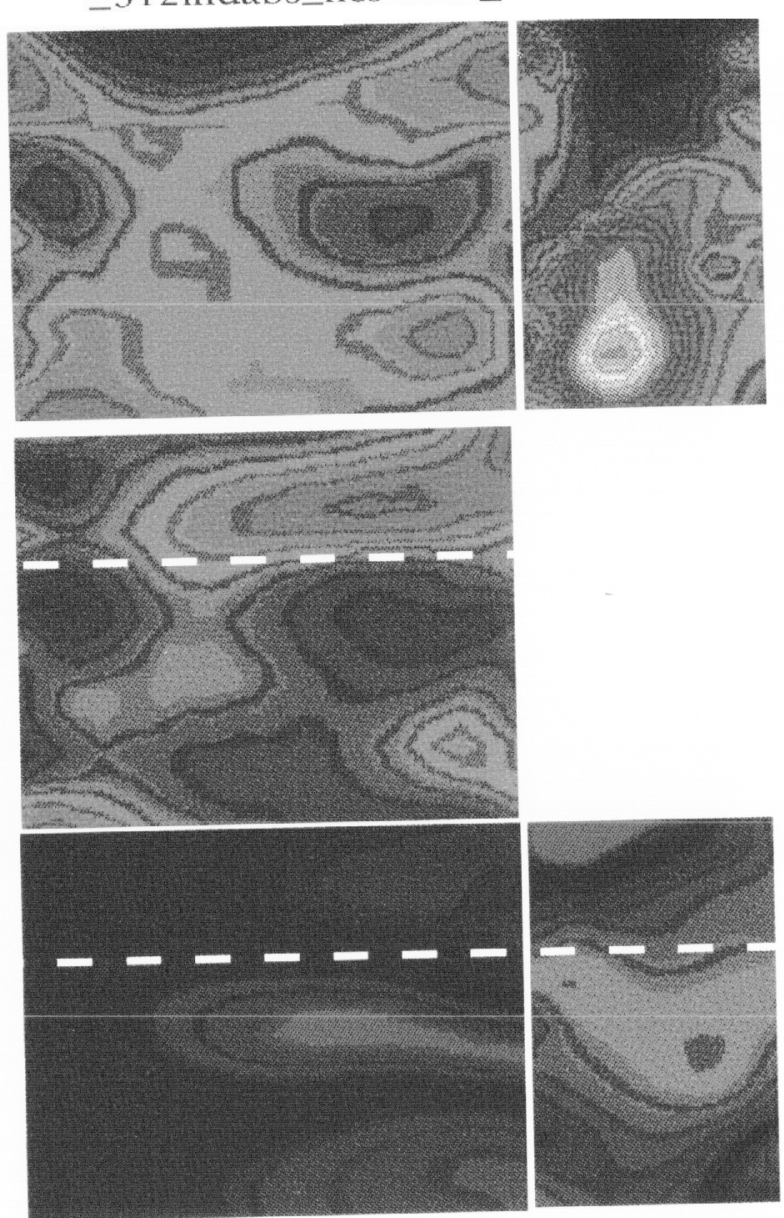

L 5

L 3

L 6

ogi0911_0840_53 ogi0911_0914_36

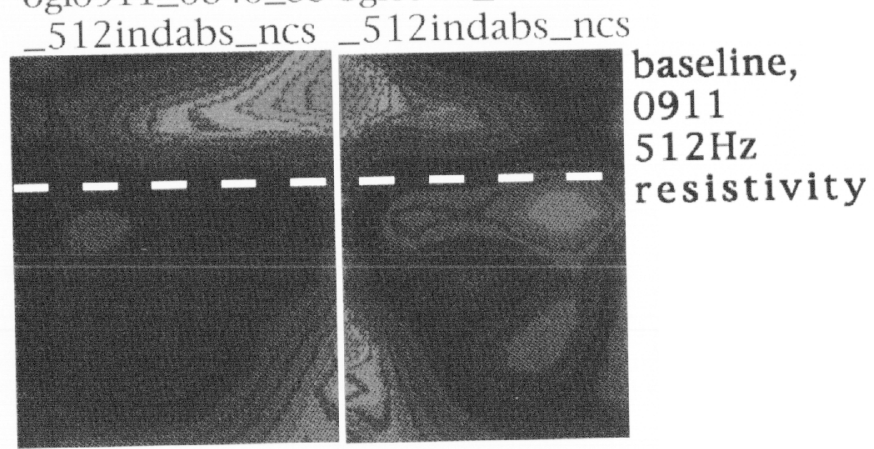

ogi0911_2147_53ogio911_2221_36

512indabs_ncs_512indabs_ncs

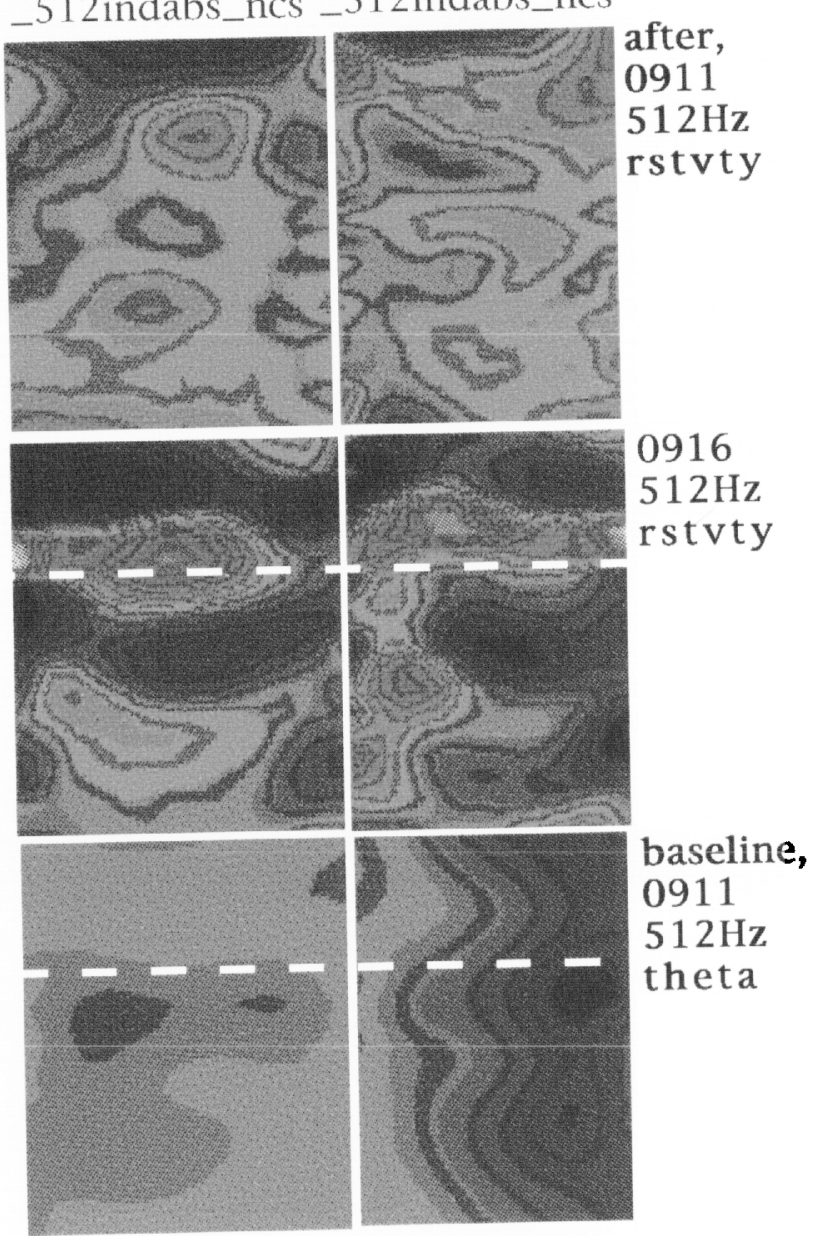




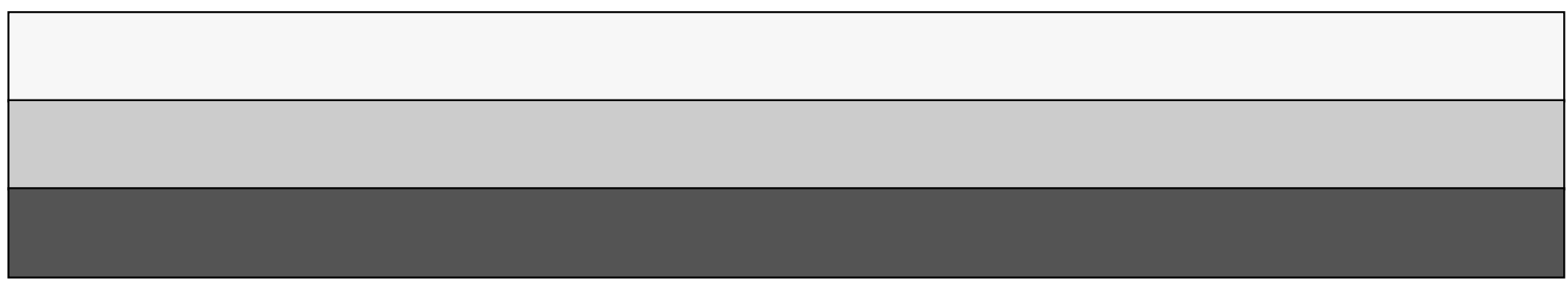

